\title{
Effect of Nursing Instructions on Self Care for Colostomy Patients
}

\author{
Walaa Ali Abd El-Rahman', Mimi Mohamed Mekkawy ${ }^{2}$, Mahmoud Thabet Ayoub ${ }^{3}$ \& Samia Youssef Sayed ${ }^{4}$ \\ 1. Demonstrator of Medical-Surgical Nursing, Faculty of Nursing, Assiut University, Egypt. \\ 2. Professor of Medical-Surgical Nursing, Faculty of Nursing, Assiut University, Egypt. \\ 3. Lecturer of General Surgery, Faculty of Medicine, Assiut University, Egypt. \\ 4. Assistant Professor of Medical-Surgical Nursing, Faculty of Nursing, Assiut University, Egypt.
}

\begin{abstract}
Background: Ostomy nurses should be able to provide nursing care not only on physiological problems but also other problems related to the ostomy. Aim of the study: To evaluate the effect of nursing instructions on self-care for colostomy patients. Hypothesis: The application of nursing instructions will have a positive effect on self- care for colostomy patients. Research design: Quasi-experimental study design (pre-post test) was used. Subjects: Thirty adult patients from both sex with abdominal operations treated by colostomy. Setting: The study was carried out at General Surgery Departments of Assuit University Hospital. Tools: (I) Pre-post colostomy knowledge Questionnaire, Tool (II): Pre-post observation checklist for colostomy self-care practices and Tool (III): The Ostomy Self-Care Index (OSCI). Result: A highly significant statistically difference was found regarding total knowledge, practice and (OSCI) scores of the studied sample pre and post(Immediate and one month) implementation of colostomy nursing instructions $(\mathrm{p}=.001 * *)$. Conclusion: It was concluded that implementation of colostomy nursing instructions had statistically significant positive effect on patient's knowledge and self-care practices. Recommendation: The patients should be included in program provided by ostomy care team for improving self care, prevention and treatment of physical and psychological complications.
\end{abstract}

\section{Keywords: Nursing Instructions, Self care \& Colostomy Patients.}

\section{Introduction}

Colostomy is a surgically created opening between the colon and abdominal wall to allow fecal elimination leaving the patient with an opening on the abdomen called stoma in which waste is passed into an appliance that must be emptied periodically(Campos et al., 2017). Colostomy can be performed on the ascending, transverse, descending or sigmoid colon and can be permanent or temporary (Herawati \& Nasution, 2019).

The effects caused by colostomy do not just exert physical and physiological influence, but also affect patients' emotional and social sphere. For these patients who need to face an ostomy after surgery, this is one of the most difficult experiences in their lives (Nieves et al., 2017). So this entails a need for integrated and planned self-care education as a means of supporting ostomates in overcoming the physical, psychological, and social difficulties, and increase self-esteem (Seo, 2019).

Ostomy nurses are responsible for managing persons with a stoma, and this specialty nursing practice continues to evolve on a global basis (Sujianto et al., 2020). Thus, comprehensive and personalized nursing care is important in order to prevent or manage complications and improve the physiological and psychosocial adjustments to ostomy patient. As a result, it will enhance the patients' self-care ability (Ayaz-Alkaya, 2019).

Self-care is defined as performing necessary activities that are basic needs of the individual and self-care ability is defined as the ability to perform these activities .By the way self-care is an important part for the adaptation of patients with stomas and healthy behaviors after surgery (Culha et al., 2016). Stoma self-care states that patients learn how to manage their stomas independently (Mohamed et al., 2017).

Operational definition

Nursing instructions refer to the use of nursing staff teaching skills to provide patients with planned learning methods, and to subsequently expand patients' health knowledge and influence their selfcare behavior.

\section{Significance of the study}

In Assiut University Hospitals through year 20182019 , it was found that there were approximately (50) cases carried out colostomy at general surgery departments (A, B and C). (Assiut University Hospitals records, 2019). From the researcher's experience; (2 years at General Surgery Departments) the researcher observed that patients undergoing colostomy face many physical and psychological problems, 
added to the long term problems of colostomy and its impact on patient's condition and interference with day-to-day living. Therefore the researcher intended to develop and implement nursing instructions of selfcare for colostomy patients in order to empower them to develop self-care ability to manage themselves.

Aim of the study

The aim of this study was:

Evaluate the effect of nursing instructions on self care for colostomy patients. through the following:

1. Assesse patients' knowledge and practice regarding colostomy self care.

2. Design and implement nursing instructions for colostomy self-care.

\section{Hypothesis}

The application of nursing instructions will have a positive effect on self- care for colostomy patients.

\section{Patients \& Methods \\ Research design}

Quasi-experimental study design (pre-post test) was utilized to conduct this study.

\section{Setting}

The study was conducted at General Surgery Departments of Assuit University Hospital (A, B and C).

\section{Subjects}

Sample of (30) adult patients from both sex with abdominal operations treated by colostomy (either a temporary or a permanent colostomy). They were selected according to inclusion criteria as; adult patients, their age ranged from 18-65 years old, and able to communicate. The exclusion criteria included people with end-stage diseases and those who suffered physical, cognitive, mental and/ or psychological disabilities that would prevent them from participating in self-care.

\section{Sample size}

The sample of 30 patients were selected by using the following equation according to (Steven, Thompson, 2012)

$$
n=\left[\frac{N \times p(1-p)}{\left.\left.\llbracket N-1 \times\left(d^{2} \div z^{2}\right)\right]+p(1-p)\right]}\right.
$$

$\mathrm{N}=$ total patient population size of 50 who attended the general surgery departments at Assiut university hospitals. During year 2018-2019.

$\mathrm{Z}=$ confidence levels is 0.95 and is equal to 1.96

$\mathrm{D}=$ The error ratio is $=0.05$

$\mathrm{P}=$ The property availability ratio and neutral $=0.50$

Tools of the Study

Three tools were utilized to collect data for this study: Tool (I): Pre-post colostomy knowledge questionnaire

It was developed by the researcher to assess Patient's knowledge about colostomy self-care based on review of literature (Mohamed et al., 2017 \& Alansari et al., 2018). It includes three parts:

Part (1): Demographic data of the patients: as name, age, sex, marital status, occupation, educational level and residence.

Part (2): Medical history of the patients: it was developed to assess past and present medical history of the patients such as causes of stoma, chronic diseases, and family history of the same disease.

Part (3): Colostomy-related knowledge: Patient's knowledge about definition, causes, types, complication of colostomy, and unusual signs to seek medical advice. As well as Knowledge about diet and physical activities.

\section{Scoring system}

This part consisted of two knowledge sections; first, patient information regarding the colostomy and unusual signs to seek medical advice (5 questions), second, information regarding diet and physical activities (6 questions). The answers were categorized and scored into complete correct (2) score, incomplete correct (1) score, incorrect (0) score. The total score for all items was (22 grades). Patients were classified as having a good knowledge if their total score was $\geq 70 \% \quad(\geq 15$ grades). while classified as having fair level of knowledge if their total score was $50 \%$ to $69 \%$ (11- 14 grades) and finally poor level of knowledge if the total score was $<50 \%$ ( $<11$ grades) (Abd El-Hay et al., 2019).

Tool (II): Pre-post observation checklist for colostomy self-care practices:

This tool was developed by the researcher after review of literature (Mohamed et al., 2017 \& Abdelmohsen, 2020) to assess patient's practices related to stoma care. This checklist consisted of 5 main categories (preparation of colostomy base and bag, removal old colostomy base and bag, cleaning and assessing stoma as well as the skin around it, irrigation and applying a new colostomy base and bag).

Each categories consisted of number of steps, preparation of colostomy base and bag (4 steps), removal old colostomy base and bag (2 steps), cleaning and assessing stoma as well as the skin around it (2 steps), irrigation (14 steps), and applying a new colostomy base and bag (7steps). (Total steps for all categories were 29).

Scoring system

Each step was observed, categorized and scored as follow: one mark for each step that was done and zero for each step that wasn't done. Those who obtained $70 \%$ or above ( $\geq 20$ grades) were considered having adequate practice, While those who obtained less than $70 \%$ (<20 grades) were considered having inadequate practice (Walker et al., 2014). 
Tool (III): The Ostomy Self-Care Index (OSCI): The Ostomy Self-Care Index (OSCI) was developed by (Villa $\boldsymbol{e t} \boldsymbol{a l . , 2 0 1 8 ) . ~ T h e ~ O S C I ~ i s ~ a ~ s e l f - r e p o r t e d ~}$ tool composed of 32 items split into four subscales that use a 5-point Likert scale (Never $=1$, Rarely $=2$, Sometimes $=3, \quad$ Often $=4$ and Always=5). These subscales include self-care maintenance (daily routine behaviors (9) items), self-care monitoring (stoma and peristomal skin recognition (8) items), self-care management (problem recognition and response behaviors (5) items) and self-care confidence (confidence in the ability to engage effectively in self-care (10) items).

\section{Scoring system}

This scale composed of 32 items, each item scored from 1-5. The maximum total score possible is 160 and the minimum possible score is 32 . This scale has a standardized score ranging between 0 and 100 the higher scores meaning better self-care. Self-care was considered adequate when total score of OSCI scale is $70 \%$ or higher and inadequate when total score of OSCI is less than70\% (Riegel et al., 2009 \& Villa et al., 2018).

\section{Nursing instructions for colostomy self-care}

These instructions were developed by the researcher based on literature review and colostomy patients' needs and level of understanding; It was prepared in the form of a booklet written in simplified Arabic language and supported by photo illustrations and colored pictures to be suitable for all patients regardless to their educational level. After completion of the nursing instruction, every patient received a copy of the booklet and another copy given to the head nurse of surgery departments as a guide for everyone admitted to these departments. It included two parts

Part I: Theoretical part: It was designed to cover the following items (anatomy of colon, definition and causes of colostomy, normal stoma appearance, daily life changes, diet regimen, unusual signs to seek medical advice, physical activities, complications, and general advices related to colostomy included(type of suitable clothing, bathing, traveling preparation, returning to the work ,sexual relationship, driving, religious practices) .

Part II: Practical part: It was concerned with colostomy self-care practices regarding to (preparation of the colostomy base and bag, removal old colostomy base and bag, cleaning and assessing stoma as well as the skin around it, irrigation and applying a new colostomy base and bag).

\section{Ethical approval}

Permission to carry out the study was obtained from the ethical committee of the Faculty of Nursing. An official letter was issued from the Dean of the Faculty of Nursing to the Head of the General Surgery
Department to collect the necessary data. Informed consent was obtained from patients or families willing to participate in the study after explanation of the nature and purposes of the study. Confidentiality and anonymity were assured. Patients had the right to refuse or participate and/or withdraw from the study without any rational at any time.

\section{Content validity and reliability}

Content validity was done by 5 experts from MedicalSurgical Nursing staff and staff of general surgery who reviewed the tools for clarity, relevance, comprehensiveness, and understanding. Minor modifications were done and correction was carried out accordingly and then the tools were designed in their final format and tested for reliability. Reliability of the tool was measured by Cronbach's alpha coefficient (r-0.72).

\section{Pilot study}

A pilot study was conducted on $10 \%$ of the study subjects ( 3 patients) to test the applicability and clarity of the tools. The data obtained from the pilot study were analyzed; no changes were done in the used tools, so the $10 \%$ of subjects selected for the pilot study were included in the study.

\section{Procedure}

The study was carried out on 3 phases:

\section{The preparatory phase}

- An official permission to conduct this study was obtained from the head of general surgery department at Assiut University Hospital.

- Preparation of the data collection tools was carried out by the researcher after extensive literature review (nursing and medical textbooks, journals, internet resources) at this phase.

- Patient agreement for voluntary participation was obtained orally.

- Every patient was interviewed 3 times, one time before applying nursing instructions and 2 times after applying nursing instructions (Immediately post, after one month).

- First meeting (pre) was done to test patients in knowledge, practice and assesse the self-care for them by using tools of data collection before provision of any information in the form of a short session of around one hour.

\section{The Implementation phase}

- At initial interview, the researcher introduced herself to initiate communication, explained the nature and purpose of the study.

- Data was collected over a period of 8 months from January to August, 2020.

- The data was collected by the researcher 2 days/week .The data was collected at morning and afternoon shifts

- The researcher implemented the colostomy nursing instructions for each patient separately or 
in small group from 2-3 patients. The sessions were given according to each patient needs. The nursing instructions were presented in theoretical and practical sessions.

- The theoretical part was conducted through lectures, and group discussion. It was provided in two sessions (about 30 mins) for each.

- The practical part was conducted through demonstration, re-demonstration, using real materials and video illustration. It was given in two sessions (25-30mins) for each.

- Each session started by a summary about what was discussed in the previous session.

- Each patient restated all instructions given to $\mathrm{him} /$ her and the researchers ensured that each patient able to use the booklet as a reference if needed at home.

- Patients were given a printed copy of the booklet which was in simple Arabic language with illustrated photographs for each practice.

- At the end, patients were informed to be in contact with the researcher by telephone for any guidance.

\section{Evaluation phase (Follow up phase)}

Evaluation was done two times immediately following completing the implementation of educational sessions and after one month (evaluation was done using tools I, II and 1 III).

\section{Statistical design}

Data entry was done using compatible personal computer by the researcher. All data was entered into statistical packages for the social sciences (SPSS) version 22.0 software for analysis and Excel for figures. The content of each tool was analyzed, categorized and then coded by the researcher. Categorical variables were described by number and percent, where continuous variables were described by mean and standard deviation (Mean, SD).Chisquare test and fisher exact test used to compare between categorical variables where compare between continuous variables by t-test and anova test. two -tailed $\mathrm{p}<0.05$ was considered statistically significant.

\section{Results}

Table (1): Frequency and percentage distribution of demographic data for the studied patients $(n=30)$.

\begin{tabular}{|c|c|c|}
\hline Variables & $\mathrm{n}=\mathbf{3 0}$ & $\%$ \\
\hline \multicolumn{3}{|l|}{ Age } \\
\hline$-18-<30$ & 1 & 3.3 \\
\hline$-30-<40$ & 5 & 16.7 \\
\hline$-40-<50$ & 14 & 46.7 \\
\hline$-\geq 50$ & 10 & 33.3 \\
\hline Mean \pm SD & \multicolumn{2}{|c|}{$47.11 \pm 11.03(18-65)$} \\
\hline \multicolumn{3}{|l|}{ Gender } \\
\hline -Male & 19 & 63.3 \\
\hline -Female & 11 & 36.7 \\
\hline \multicolumn{3}{|l|}{ Marital status } \\
\hline -Single & 7 & 23.3 \\
\hline -Married & 23 & 76.7 \\
\hline \multicolumn{3}{|l|}{ Education level } \\
\hline -Illiterate & 7 & 23.3 \\
\hline -Read and write & 8 & 26.7 \\
\hline -Secondary & 12 & 40.0 \\
\hline -University & 3 & 10.0 \\
\hline \multicolumn{3}{|l|}{ Occupation } \\
\hline -House wife/not working & 12 & 40.0 \\
\hline -Working & 18 & 60.0 \\
\hline \multicolumn{3}{|l|}{ Residences } \\
\hline -Urban & 11 & 36.7 \\
\hline -Rural & 19 & 63.3 \\
\hline
\end{tabular}


Table (2): Frequency and percentage distribution of medical history among the studied patients $(n=30)$

\begin{tabular}{|l|c|c|}
\hline \multicolumn{1}{|c|}{ Medical history } & $\mathbf{n}=\mathbf{3 0}$ & $\%$ \\
\hline Causes of stoma & 15 & 50.0 \\
\hline - Colorectal cancer & 1 & 3.3 \\
\hline - Diverticulitis & 4 & 13.3 \\
\hline - Colon and rectum trauma & 6 & 20.0 \\
\hline - Intestinal obstruction & 4 & 13.3 \\
\hline - Others & & 50.0 \\
\hline Chronic diseases & 15 & 13.3 \\
\hline - Hypertension & 4 & 6.7 \\
\hline - Diabetes mellitus & 2 & 3.3 \\
\hline - Heart disease & 1 & 3.3 \\
\hline - Bronchial asthma & 1 & 23.3 \\
\hline - Kidney disease. & 7 & 20.0 \\
\hline - None & & 80.0 \\
\hline Family history for colostomy & 6 & \\
\hline - Yes & 24 & \\
\hline - No & \multicolumn{2}{|c|}{} \\
\hline
\end{tabular}

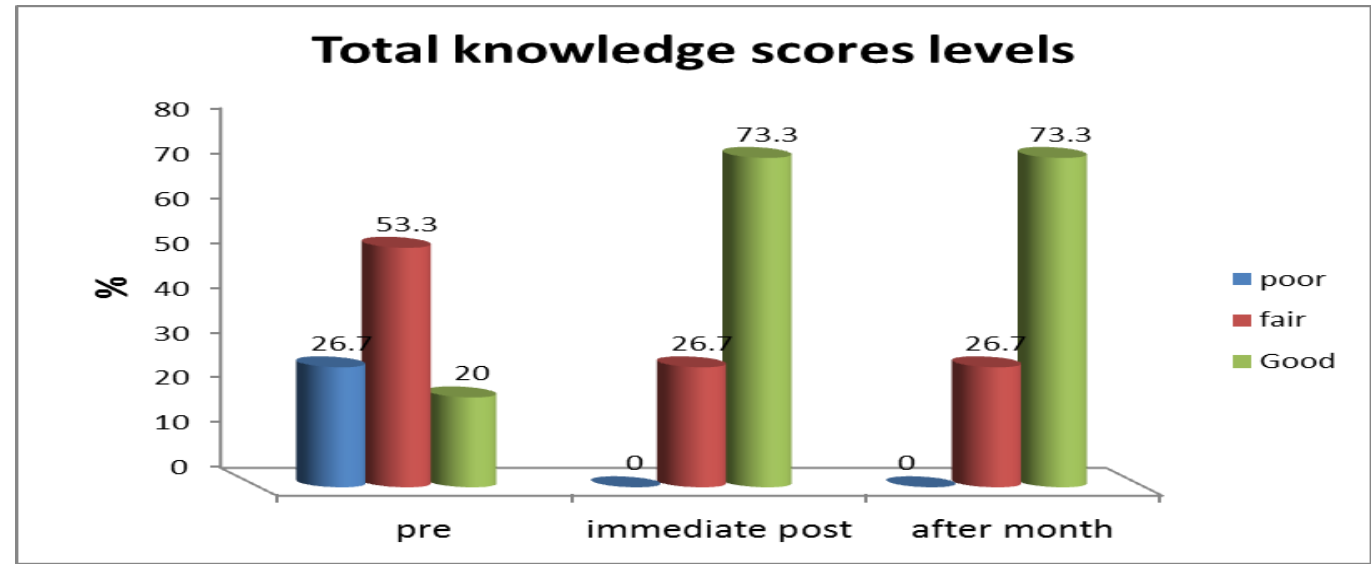

Chi-square test $* *$ Significant difference at p. value $<0.01$

Fig. (1): Total knowledge scores levels obtained by patients pre and post (Immediate and one month) implementation of colostomy nursing instructions $(n=30)$

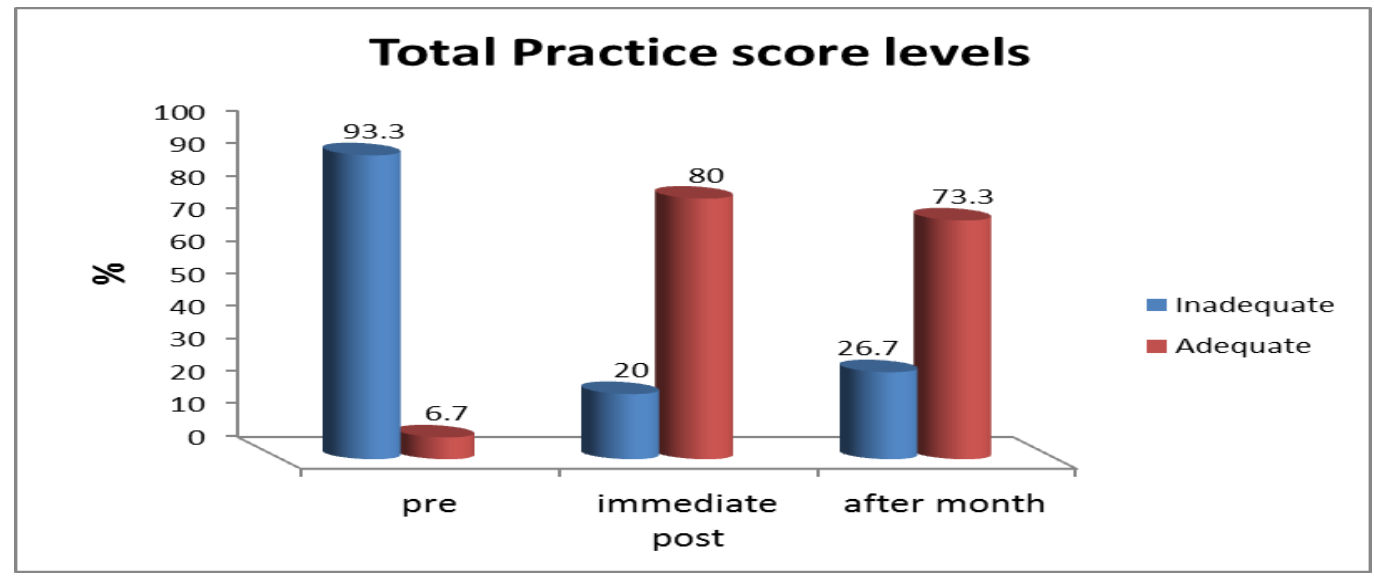

- Chi-square test $* *$ Significant difference at p. value $<0.01$

Fig (2): Total Practice scores levels obtained by patients pre and post (Immediate and one month) implementation of colostomy nursing instructions $(n=30)$ 
Table (3): The mean scores of studied patients regarding to total and subtotal of the Ostomy Self-Care Index pre and post (Immediate and one month) implementation of colostomy nursing instructions $(n=30)$

\begin{tabular}{|l|c|c|c|c|c||}
\hline \multirow{2}{*}{ OSCI subscales } & \multirow{2}{*}{ Max Score } & Pre & $\begin{array}{c}\text { Immediate } \\
\text { post }\end{array}$ & $\begin{array}{c}\text { after one } \\
\text { month }\end{array}$ & \multirow{2}{*}{ P. value } \\
\cline { 3 - 5 } & & Mean \pm SD & Mean \pm SD & Mean \pm SD & \\
\hline Self-care maintenance & 45 & $26.73 \pm 4.13$ & $40.5 \pm 2.52$ & $40.97 \pm 2.03$ & $<0.001^{* *}$ \\
\hline Self-care monitoring & 40 & $23.53 \pm 3.29$ & $33.67 \pm 2.71$ & $34.93 \pm 2.07$ & $<0.001^{* *}$ \\
\hline Self-care management & 25 & $16.53 \pm 2.29$ & $22.8 \pm 1.77$ & $23.17 \pm 1.02$ & $<0.001^{* *}$ \\
\hline Self-care confidence & 50 & $29.87 \pm 4.05$ & $43.7 \pm 2.42$ & $45 \pm 2.45$ & $<0.001^{* *}$ \\
\hline Total ostomy Self-care index & $\mathbf{1 6 0}$ & $\mathbf{9 6 . 6 7} \pm \mathbf{1 2 . 1 1}$ & $\mathbf{1 4 0 . 6 7 \pm 6 . 1 4}$ & $\mathbf{1 4 4 . 0 7} \pm \mathbf{5 . 3 8}$ & $<0.001^{* *}$ \\
\hline
\end{tabular}

- One-way Anova Test ${ }^{* *}$ Significant difference at p. value $<0.01$

Table (4): Score levels of total Ostomy Self-Care Index (OSCI) pre and post (Immediate and one month) implementation of colostomy nursing instructions $(n=30)$

\begin{tabular}{|c|c|c|c|c|c|c|c|}
\hline \multirow{2}{*}{ Total Ostomy Self-care index } & \multicolumn{2}{|c|}{ Pre } & \multicolumn{2}{|c|}{ Immediate } & \multicolumn{2}{|c|}{ after month } & \multirow{2}{*}{ P. value } \\
\hline & No & $\%$ & No & $\%$ & No & $\%$ & \\
\hline Inadequate & 26 & 86.7 & 2 & 6.7 & 3 & 10.0 & \multirow{2}{*}{$<0.001 * *$} \\
\hline Adequate & 4 & 13.3 & 28 & 93.3 & 27 & 90.0 & \\
\hline
\end{tabular}

- Chi-square test $* *$ Significant difference at $p$. value $<0.01$

Table (5): Correlation between total score of knowledge and self-care practices of patients pre and post (Immediate and one month) implementation of colostomy nursing instructions $(\mathrm{n}=\mathbf{3 0})$

\begin{tabular}{|l|c|c|}
\hline \multirow{2}{*}{ Total practice score } & \multicolumn{2}{|c|}{ Total knowledge score } \\
\cline { 2 - 3 } & $\mathrm{R}$ & $\mathrm{P}$ \\
\hline -Pre & 0.288 & 0.122 \\
\hline -Immediate post & 0.523 & $0.003^{* *}$ \\
\hline -After one month & 0.455 & $0.011^{*}$ \\
\hline
\end{tabular}

*Statistically Significant Correlation At P. value $<0.05$

**Statistically Significant Correlation At P. value $<0.01$

Table (1): Illustrated that; about half of the studied patients $(46.7 \%)$ their age from 40 to $<50$ with mean \pm SD $47.11 \pm 11.03$ years. Regarding gender, it was found that more than half $(63.3 \%)$ of studied patients were males, the majority of them $(76.7 \%)$ were married and more than one third $(40.0 \%)$ of studied patients had secondary education. Regarding occupation; it was found that more than half $(60.0 \%)$ were working and the rest $(40.0 \%)$ were house wives. As well as $(63.3 \%)$ of studied sample were lived in rural regions.

Table (2): Revealed that; the stoma causes for half of studied patients $(50.0 \%)$, were colorectal cancer and $(20 \%)$ were intestinal obstruction. Concerning chronic diseases, it was found that half of the studied patients $(50.0 \%)$ complained from hypertension. while the majority of them $(80 \%)$ had no family history of colostomy.

Figure (1): Demonstrated that, $(53.3 \%)$ of the studied patients had fair knowledge score level pre implementation of instruction compared to (73.3\%) of them had good knowledge score level post (immediate and one month) implementation of colostomy nursing instructions. there was a highly significant statistically difference between pre and post (immediate and one month) implementation of colostomy nursing instructions $\left(\mathrm{p}<.001^{* *}\right)$.

Figure (2): Showed that the majority of studied patients had inadequate practice score level pre implementation of colostomy nursing instructions. While post (immediate and one month) implementation of colostomy nursing instructions, they had adequate practice score level $(80.0 \%$ and $73.3 \%$ respectively). And there was a highly significant statistically difference between pre and post (immediate and one month) implementation of colostomy nursing instructions with $(\mathrm{p}<0.001)$.

Table (3): Showed that a significant statistically differences was found between pre and post (immediate and one month) implementation of colostomy nursing instructions regarding Ostomy Self Care Index subscales with $(\mathrm{p}<0.001)$.

Table (4): Showed that, $(86.7 \%)$ of the studied subjects had inadequate ostomy self-care pre implementation of colostomy nursing instructions, while post (immediate and one month) 
implementation of colostomy nursing instructions, the majority of them had adequate ostomy self-care (93.3\% and $90.0 \%$ respectively). There was a highly significant statistically difference between pre and post (immediate and one month) as regarding to the total score of Ostomy Self-Care Index ( $<<0.001 * *)$.

Table (5): Revealed that no significant correlation between knowledge, and self-care practices pre implementing colostomy nursing instructions $(\mathrm{r}=0.288, \mathrm{P}=0.122)$. A significant correlation was found post (immediate and one month) implementation of colostomy nursing instructions between the total knowledge score and total self-care practices $(\mathrm{r}=0.523, \mathrm{P}<0.003$ and $\mathrm{r}=0.455, \mathrm{P}<0.011$ respectively).

\section{Discussion}

Colostomy patients face huge problems in terms of need to receive suitable information to adapt them to this new situation. The nurse as an educator must focus on giving appropriate health teaching to patients with generous feedback and evaluation to promote teaching .Preoperative and postoperative colostomy patient education can facilitate adjustment, reduce complications, and improve overall quality of life (Abdelmohsen, 2020).

Thus, the present study was conducted to evaluate the effect of nursing instructions on self -care for colostomy patients.

Regarding Demographic data of the studied patients, the present study revealed that about half of the studied patients, their age from 40 to <50with mean \pm SD $47.11 \pm 11.03$ years. This finding supported by (Wong et al., 2015). Who reported that ostomy creation tends to strike in middle age between 40-50 age. While it contradicts the results by (Abdelmohsen, 2020) who found that the mean age \pm SD of colostomy patients was $35.6 \pm 14.4$ years. From the researcher point of view, this result may be due to the age of greater than 40 years is considered one of the risk factors for colon cancer.

Concerning the gender, the current study revealed that the majority of the studied patients were predominantly males; this finding was similar to study performed by (Hegazy et al., 2014). Who reported that, gender of patients undergoing colostomy was males $(60.0 \%)$. this finding was in disagreement with (Kadam \& Shinde, 2014) who reported that colostomy was higher in females $(66.66 \%)$. From the researcher opinion; this may be because most of men are heavy smoking and had fast food and these factors increase the risk of developing colorectal cancer.

Concerning the causes of colostomy; the present study revealed that half of the studied patients had colorectal cancer. This comes in the same line with
(Wehida, et al., 2015) who reported that (65.0\%) had an ostomy for bowel and colon cancer reason.

In accordance with the study result of (Erwin, 2013) who supported this finding as he found that the etiology for colostomy are diseases condition requiring removal of the distal bowel (for example, colorectal cancer).As well as(Alansari et al., 2018) pointed that $58 \%$ of stoma surgery caused by colorectal cancer.

On the other hand this finding contradicted with the study of (Engida, et al., 2016) entitled with "Types and indications of colostomy and determinants of outcomes of patients after surgery". They mentioned that the indications for colostomy formation were (46.6\%) due to gangrenous sigmoid volvulus, (21\%) for colorectal cancers, and $(12.8 \%)$ for abdominal injuries. As well as the study done with (Ahmed et al., 2018) revealed that the main indication for colostomy formation was intestinal obstruction followed by trauma to abdominal wall.

Moreover, the present study showed that the majority of the studied patients had chronic diseases, which was supported by (Abdulmutalib et al., 2018) who stated that more than half of the patients had chronic diseases. This finding was supported by (Cheng et al., 2013), who discussed that ostomy patients with chronic diseases have a negative impact on stoma self-care because they may affect their daily activities and lead to change in the level of self-care this finding was disagreement with the study conducted by (Werth et al., 2014), who revealed that the majority of the patients have no chronic disease.

As regard to family history of colostomy, this study revealed that the majority of the studied patients with no family history, this result agreed with (Mohamed et al., 2017) who stated that $96.7 \%$ of patients didn't have family history for stoma. Likewise (Culha et al., 2016) who reported that the there was no one who experienced stoma surgery in their families from the patients.

Considering total patients' knowledge about colostomy, the results of this study showed that most of patients had good level of knowledge post(immediate and one month ) implementation of the colostomy nursing instructions compared to pre test. This finding was supported by (Mohamed et al., 2017 \& Abdelmohsen, 2020) who mentioned that a highly statistically significant difference was found regarding total knowledge score of the studied sample pre and post application of the structured patient education.

This finding was in the same line with (Chauhan, et al, 2017) who reported that "Comparison of pre test score with post test score was analyzed and found that there was statistically significant increase in the knowledge score obtained by subjects towards 
colostomy care of patient. The knowledge score gained by the respondents in the results showed that the mean value of knowledge in pre test was 8.43 and at post test was 17.1 , the " $p$ " value for the test is $0.05 \%$.

This study finding was in accordance with the study of (Hegazy et al., 2014) entitled as" Outcomes of Educational Guidelines on Awareness and Self Efficacy Among Patients with Permanent Colostomy" , This study revealed that patients' knowledge about colostomy care significantly improved post the education compared to pre education. (Lo et al., 2011 \& Cheng et al., 2013) stated that the stoma knowledge scores of individuals increased upon the training.

Another finding in the present study regarding the colostomy self-care practices, revealed that there is a highly significant difference between pre and post( immediate and one month) implementation of colostomy nursing instructions, which was supported by( Hegazy et al., 2014), who reported that significant improvement was indicated in post education guidelines compared to pre assessment.

This study result is congruent with (Mohamed et al., 2017) who reported that there was a significant improvement between the items of self-care practice. Furthermore, this result comes in in the same line with the study of (Herawati \& Nasution, 2019), who concluded that there is an effect of stoma education on the self-care ability of patients with colonic stoma so that stoma-based education can help support and improve the ability of self-care of patients with colon stoma.

Also, this result was in accordance with the results by (Abdelmohsen, 2020), who concluded that the structured patient education was found to be effective in enhancing patient's knowledge and practices regarding stoma. Otherwise (Culha et al., 2016) stated that, self-care scores increased in both intervention and control groups 3 weeks later and the increasing extent in the intervention group was higher than the control group $(\mathrm{p}<0.001)$

Regarding to Ostomy Self-Care Index (OSCI)) the result of the present study revealed that there was a highly statistically significant difference between pre and post (Immediate and one month) as regarding to the total and subtotal score of Ostomy Self-Care Index .These results were in the same line with (Giordano et al., 2020) who reported that generally, patients had adequate self-care maintenance and selfcare monitoring, with scores ranging between 76.44 and 77.23 .

On the other hand, these finding disagreed with (Giordano et al., 2020) who mentioned that some specific self-care management and self-care confidence behaviors were inadequate.
Regarding the correlation between total score of knowledge and self-care practices, the current study indicated that there was a significant correlation between the total level of knowledge and total selfcare practices post (immediate and one month) implementation of colostomy nursing instructions . This finding was in agreement with (Hegazy et al., 2014), who stated that there was a positive correlation between knowledge and practices. Which mean the more increase knowledge level, the greater ability to perform the activity of daily livings. Also, this study was congruent with (Mohamed et al., 2017) who reported that there was a positive correlation between knowledge and self-care practices after implementing an educational program.

Likewise, (Qalawa \& Moussa,2019) clarified that there is a statistically significant correlation between patient's knowledge scores and practice among the studied patients with colostomy in post educational implementation phases comparing to pre test $(\mathrm{Ps}=$ $0.010)$.

\section{Conclusion}

On the light of current study results, it can be concluded that implementation of nursing instructions had statistically significant positive effect on knowledge and self-care practices among colostomy patients, self-care practices is an important part for the adaptation of colostomy patients after surgery . These findings justified the research hypothesis.

\section{Recommendation}

Based on the results of the present study, the following recommendations were suggested: -

- Training program for the patients should be conducted to provide nursing instructions and training for all colostomy patients regarding self care in different hospitals.

- Implementing an ostomy care team in outpatient clinic from specialist surgeons, stoma nurse, psychotherapist, dietitians and social worker is important for providing specific stoma care to enhance the patients self care practice.

- Further research studies are needed to focus on studying the factors affecting quality of life for colostomy patients.

\section{References}

- Abd El-Hay S., Mohamed H., \& Sharshor S., (2019): Self- Care Knowledge and Practice for Patients with Permanent Stoma and their Effect on Their Quality of Life and Self Care Efficacy, An International Peer-reviewed Journal , Vol. (60), No. (4), P.p 131-138.

- Abdelmohsen S., (2020): Effectiveness of Structured Education on Patient's Knowledge 
and Practice Regarding Colostomy Care. AsiaPacific Journal of Oncology Nursing, Vol. (7), No. (4), P.p 370-374.

- Abdulmutalib I., Al Nagshabandi E., \& Alansari S., (2018): Effect of an Educational Protocol on Knowledge and Self-Care Practices among Patients with the Intestinal Ostomy. American Journal of Nursing, Vol. (6), No. (6), P.p553-561.

- Ahmed M., Mohammed E., Tohamy T., \& Mohammed J., (2018): Effect of A Designed Nursing and Patients Self Care Protocol on Reducing the Colostomy and Peristomal Skin Complications among the Elderly Patients, Minia Scientific Nursing Journal, Vol. (4) No.(1), P.p6875.

- Alansari S., Al Nagshabandi E., \& Abdulmutalib I., (2018): The Effectiveness of Implementing a Designed Educational Protocol Regarding knowledge among clients with Intestinal OstomyAmerican Journal of Nursing, Vol. (10), No. (4), P.p 24-30.

- Assiut University Hospitals records, (2019).

- Ayaz-Alkaya S., (2019): Overview of psychosocial problems in individuals with stoma: A review of literature. International Wound Journal, Vol. (16) No. (1), P.p 243-249.

- Campos K., Bot L., Petroianu A., Rebelo P., Souza A., \& Panhoca I., (2017): The impact of colostomy on the patient's life. Journal of Coloproctology (Rio de Janeiro), Vol. (37), No. (3), P.p 205-210.

- Chauhan Y., Sreedharan M., \& Jindal S., (2017): Efficacy of structured teaching programme on patient's knowledge regarding colostomy care, Scientific Research International Journal of Recent Scientific ,International Journal of Recent Scientific Research. Vol. (8), No. (11), P.p 21378-21382.

- Cheng F., Meng A., Yan L., \& Zhang Y., (2013): The Correlation between Ostomy Knowledge and Self-Care Ability with Psychosocial Adjustment in Chinese Patients with a Permanent Colostomy: Descriptive Study, Ostomy Wound Management ;Vol. (59), No. (7), P.p.35-38.

- Culha I., Kosgeroglu N., \& Bolluk O., (2016): Effectiveness of Self-care Education on Patients with Stomas, Journal of Nursing and Health Science, Vol. (5), No. (2), P.p 70-76.

- Engida A., Ayelign T., Mahteme B., Aida T., \& Abreham B., (2016): Types and indications of colostomy and determinants of outcomes of patients after surgery. Ethiopian journal of health sciences, Vol. (26), No. (2), P.p117-122.
- Erwin P., (2013): Ostomy care and rehabilitation in colorectal cancer. Oncology nursing journal, Vol. (22), No. (3), P.p174-77.

- Giordano V., Nicolotti M., Corvese F., Vellone E., Alvaro R., \& Villa G., (2020): Describing self-care and its associated variables in ostomy patients. Journal of Advanced Nursing. P.p1-11.

- Hegazy S., Ali Z., Mahmoud A., \& Abou-Zeid A., (2014): Outcomes of Educational Guidelines on Awareness and Self-Efficacy among Patients with Permanent Colostomy. New York Science Journal, Vol. (7), No. (3), P.p25-32.

- Herawati L., \& Nasution S., (2019): The Influence of Education About Stoma on Self Care Ability in Patients with Colostomy. International Journal of Current Research, Vol. (11), No. (07), P.p 5556-5559.

- Kadam A., \& Shinde M., (2014): Effectiveness of structured education on caregiver's knowledge and attitude regarding colostomy care. International Journal of Science and Research (IJSR), Vol. (3), No. (4), pp.586-593.

- Lo S., Wang Y., Wul Y., Hsu M., Chan S., \& Hayter M., (2011): Multimedia education program for patients with a stoma: Effectiveness evaluation. Journal of Advanced Nursing; Vol. (67), P.p 68-76.

- Mohamed S., Salem G., \& Mohamed H., (2017): Effect of self-care colostomy, management program on self-efficacy among patients with American Journal of Nursing Research, Vol. (5), No. (5), P.p 191-199.

- Nieves C., Díaz C., Celdrán-Mañas M., Morales-Asencio J., Hernández-Zambrano S., \& Hueso-Montoro C., (2017): Ostomy patients' perception of the health care received. Latin American Journal of Nursing, Vol. (25) ,P.p e2961-e2961.

- Qalawa A., \& Moussa M., (2019): Effectiveness of a Multimedia Educational Package for Cancer Patients with Colostomy on Their Performance, Quality of Life \& Body Image, International Journal of Nursing Science Vol. (9) , No. (3), P.p 53-64.

- Riegel B., Lee C., Dickson V., \& Carlson B., (2009): An update on the self-care of heart failure index. The Journal of cardiovascular nursing, Vol. (24), No. (6), P.p 485-497.

- Seo H., (2019): Effects of the frequency of ostomy management reinforcement education on self-care knowledge, self-efficacy, and ability of stoma appliance change among Korean hospitalised ostomates. International wound journal, Vol. (16), No. (1), P.p21-28. 
- Steven K., Thompson, (2012): sample size, Sampling, chapter (4), Third Edition, Wiley, P.p 59-60.

- Sujianto U., Billy R., \& Margawati A., (2020): Family's Experience: Nursing Care for Colorectal Cancer Patients with Colostomy. Nurse Media Journal of Nursing, Vol. (10) No. (1), P.p 96-107.

- Villa G., Vellone E., Sciara S., Stievano A., Proietti M., Manara D., \& Pantaleo G., (2018): Two new tools for self-care in ostomy patients and their informal caregivers: Psychosocial, clinical, and operative aspects. International Journal of Urological Nursing, Vol. (13), No.(1), P.p 23-30.

- Wahida S., Ibrahim S., \& Abd El-fatah G., (2015): The Impact of Implementing Educational Modules on Quality Of Life of Patients with Permanent Colostomy. Journal of Nursing and Health Science, Vol. (4), No. (3), P.p 42-50.

- Walker B., Colledge N., Raston S., \& Peman I., (2014): Assessment and management of clinical problem, chapter (18), principles and practice of medicine, $22^{\text {nd }}$ ed,Elsevier,604.

- Werth S., Schutte D., \& Stommel M., (2014): Bridging the gap: perceived educational needs in the inpatient to home care setting for the person with a new stoma. Journal of Wound, Stoma \& Continence Nursing; Vol. (41), No. (6), P.p 566572.

- Wong C., Chen J., Charlotte L., Sham M., \& Lam C., (2015): Systematic review recommends the European Organization for Research and Treatment of Cancer colorectal cancer-specific module for measuring quality of life in colorectal cancer patients. Journal of Clinical Epidemiology, Vol. (68), No. (3), pp.266-278. 